\title{
THE DEGRADATION OF EPOXY RESIN-COATED ZnO VARISTORS AT ELEVATED TEMPERATURES AND AMBIENT HUMIDITY CONDITIONS
}

\author{
JIANY ING LI ${ }^{a, *}$, SHENGTAO LI $I^{a, \dagger}, M \cdot A \cdot A L I M^{b,+}$ and G. CHEN ${ }^{c, \oplus}$ \\ aState Key Laboratory of Electrical Insulation for Power Equipment, Xi'an J iaotong U niversity, \\ $X i$ 'an, 710049, China; ' ${ }^{D}$ epartment of Electrical Engineering, Alabama A \& M U niversity, \\ P.O. Box 297, 202 Engineering and Technology Building, Normal, Alabama 35762, U.S.A.; \\ ${ }^{C} D$ epartment of Electronics and Computer Engineering, U niversity of Southampton, \\ Southampton SO 17 1BJ, U.K.
}

(Received 18 December 2002; In final form 21 March 2003)

\begin{abstract}
The degradation of the epoxy resin-coated commercial $\mathrm{ZnO}$ varistors at elevated temperatures and ambient humid conditions has been investigated experimentally. It has been observed that the leakage current of the $\mathrm{ZnO}$ varistors increases under the voltage stress at elevated temperatures with ambient humidity content. The change in the leakage current corresponding to a fixed electric field with respect to the initial current is taken as the dimensionless degradation index. This index is monitored at various experimental conditions in conjunction with the curing condition of the epoxy resin powder. The results are carefully evaluated, and it has been found that the diffusion process of the moisture into the $\mathrm{ZnO}$ varistors plays a key role in the degradation process provided that these varistors had excellent property to begin with. The ionisation of the moisture at the interface between the $\mathrm{ZnO}$ block and the epoxy resin coating leads to the increase of the leakage current. Furthermore, the role of the ambient pressure corresponding to the elevated temperatures is considered as the variable to the degradation process. These data are also monitored and analysed as a function of time.
\end{abstract}

Keywords: Zinc oxide (ZnO) ceramics; Varistor; Degradation; Epoxy resin powder; A geing; Insulating material

\section{INTRODUCTION}

Zinc oxide $(\mathrm{ZnO})$ varistor is a highly non-linear semiconducting device that is widely used as a transient voltage surge protector in the electrical and electronic systems. The highly nonlinear current-voltage (I-V) characteristic results from the double Schottky barrier formed across the grain boundaries during the sintering process of the $\mathrm{ZnO}$ ceramics. The polycrystalline $\mathrm{ZnO}$ varistor is a ceramic material with small additions of $\mathrm{Bi}_{2} \mathrm{O}_{3}, \mathrm{Sb}_{2} \mathrm{O}_{3}, \mathrm{SiO}_{2}$ and other oxide constituents. These varistors are always placed in parallel with the systems to be protected. Thus, they are subjected to constant electric stress due to the applied voltage. During this constant applied electric stress varistors tend to degrade, implying an increase in

\footnotetext{
* E-mail: lijy@mail.xjtu.edu.cn

E-mail: sli@mail.xjtu.edu.cn

* Corresponding author. E-mail: malim@aamu.edu

- E-mail: gc@ecs.soton.ac.uk
} 
leakage current. Therefore, it is important to understand the behaviour of the varistors under the constant electric stress.

The varistor recipe and the manufacturing methods have attained maturity over the years but the degradation process of the $\mathrm{ZnO}$ device is still not fully understood. How to control or reduce the long-term degradation effect remains one of the major challenges for the investigators. In general, the degradation [1-8] refers to a gradual increase (steady or slow) in leakage current under the electric pulse stress or constant applied voltage. $M$ any early investigators [9-12] had recommended some remedial steps such as heat-treatment (annealing) in conjunction with the adjustment in the varistor formulation and processing variables to control the degradation process for better stability of the device under applications. Gupta et al. $[13,14]$ suggested that ions within the depletion layer diffuse preferentially in the direction of the current flow. This mechanism was originally proposed as a plausible concept in the EPRI report [15]. These ions combine with the defects that form the Schottky barrier across the grain boundaries. As a result, the potential barrier is lowered, leading to an increase in leakage current. A nother plausible mechanism [16] assumes that oxygen is evolved from the grain boundary during the degradation process, which leads to the decrease in the interface states and thereby the potential barrier. The concept of lowering the potential barrier is postulated in both models, and the models can explain to some extent the degradation phenomena observed in the $\mathrm{ZnO}$ varistors. However, the above principles only concern the degradation of pure $\mathrm{ZnO}$ ceramics. When used as commercial varistors, the ceramic blocks should be coated with a coating made from epoxy resin pow der. The role of the coating is to prevent the contamination and provide the varistor ceramics with a stable working condition.

The degradation of the commercial ZnO varistor coated with an epoxy resin layer may involve other factors apart from the degradation of the $\mathrm{ZnO}$ varistor block itself. Literature search reveals that little attention is received on this issue. Thus, this paper reports an investigation into the degradation caused by elevated temperatures and ambient humidity content for the epoxy resin-coated ZnO varistor discs.

\section{EXPERIMENT}

The commercial ZnO varistor discs of good quality are used in the experiment. Each of these discs has a diameter of $10 \mathrm{~mm}$ and a thickness of $1 \mathrm{~mm}$. The original value of the leakage current $\left(\mathrm{I}_{1}\right)$ of each sample measured at $75 \%$ of the varistor voltage, $\mathrm{V}_{1 \mathrm{~mA}}$, is nearly the same. This value remained less than $5 \mu \mathrm{A}$. The epoxy resin powder used in the experiment is an organic material and its exact chemical nature is not known, due to the proprietary reasons. However, it is a proven insulating material possessing a resistivity value at least two orders higher than the $\mathrm{ZnO}$ varistors.

Three processing temperatures $\left(120^{\circ} \mathrm{C}, 150^{\circ} \mathrm{C}\right.$, and $\left.180^{\circ} \mathrm{C}\right)$ with four different processing time durations $(0.5 \mathrm{~h}, 1.0 \mathrm{~h}, 1.5 \mathrm{~h}$, and $2.0 \mathrm{~h})$ corresponding to each of these temperatures are used in curing the epoxy resin powder to form the coating on the $\mathrm{ZnO}$ varistor discs. The number of samples prepared using these processing combinations exceeded 10 and, thus, repeated experiments were conducted to assure the observations.

Three distinct experimental conditions are used in conducting the investigation. Each of these conditions is noted carefully and described below.

1. Normal Method: the temperature is elevated to $40{ }^{\circ} \mathrm{C}$ and ambient relative humidity is maintained at $95 \%$. This condition is often applied to long-term experiments. U sually long-term experiment implies the monitoring of the change in leakage current for at least 1000 hours. 
2. Pressurised Vapour M ethod: the temperature is elevated to $125^{\circ} \mathrm{C}$ and an ambient vapour pressure of $0.137 \mathrm{M} \mathrm{Pa}$ is obtained. The values of temperature and vapour pressure are interrelated since they were achieved by heating distilled water in an enclosed vessel. Compared with the normal method, the temperature and vapor pressure were greatly enhanced. Thus it is a much more severe condition and it will take a much shorter time for the samples to fail. This condition is often applied to short-term experiments based on its elevated temperature and pressure.

3. Water Boiling Method: in this condition boiling water is chosen to provide the elevated temperature and ambient humidity. The sample was immersed in the boiling water for different times such as 1, 2, 3, 4 hours and then was measured under dry and room temperature conditions.

In order to give a quantitative description of the degradation the ratio of leakage currents, $m$, is defined as

$$
m=\frac{l_{1 t}-l_{10}}{l_{10}} \times 100 \%,
$$

where $I_{10}$ is the initial leakage current and $I_{1 t}$ is the leakage current at any instant of time, $\mathrm{t}$, during the measurement process. The ratio of water absorption, $\mathrm{n}$, for each $\mathrm{ZnO}$ varistor sample is applied to evaluate the change in mass of the sample during the degradation period. The parameter $\mathrm{n}$ is based on the weight change in $\mathrm{ZnO}$ varistors and defined as

$$
\mathrm{n}=\frac{\mathrm{W}_{\mathrm{t}}-\mathrm{W}_{0}}{\mathrm{~W}_{0}} \times 100 \%,
$$

where $W_{0}$ is the initial mass of the sample and $W_{t}$ is the mass of the same sample after immersing for a time t.

The $\mathrm{ZnO}$ varistors with epoxy resin coating were first put into various testing conditions for different durations and then the parameters of $m$ and $n$ were obtained under dry and room temperature conditions.

\section{RESULTS AND DISCUSSION}

\subsection{The Degradation of ZnO Varistors Coated with Epoxy Resin Under Various Conditions}

A series of experiments has been carried out to ensure the repeatability. Since a good reproducibility is achieved, only a few selected data are presented here. Figure 1 represents the behaviour of $\mathrm{m}$ for the samples prepared using curing condition $120^{\circ} \mathrm{C}$ with $1.5 \mathrm{~h}$ processing time duration. It can be seen that the pressurised vapour method yields a serious degradation effect. The value of $\mathrm{m}$ shows an increase of $75 \%$ after the sample has been stressed for 5 hours. It is more than likely that such a device approaches thermal runaway [17-19] in a very short time. Eventually the device is expected to fail.

There is a small rise of $\mathrm{m}$ within the first $1 \mathrm{~h}$ and then remaining nearly the same. On many occasions commercial $\mathrm{ZnO}$ varistor blocks exhibit similar starting behaviour within the first $1 \mathrm{~h}$ or $2 \mathrm{~h}$ and then stabilise for the rest of the experiment (say $1000 \mathrm{~h}+$ ). A fter $5 \mathrm{~h}$ the sample began to show an increase in the leakage current, slowly approaching the degradation of the device. The elevated temperature and humidity will lead to the increase of leakage current $I_{1}$. When it reaches a specific value (generally $8-10 \mu \mathrm{A}$ for samples present in this paper), l, will 


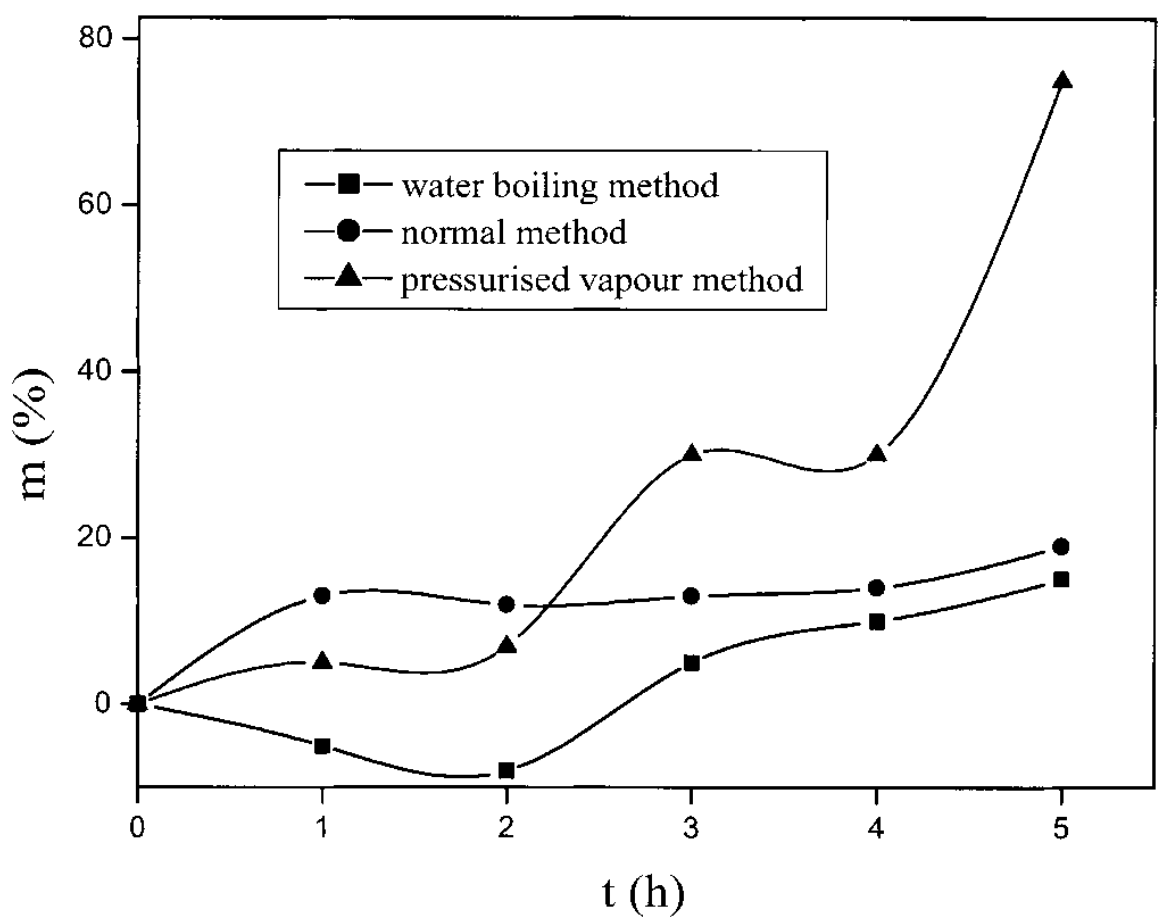

FIGURE 1 The relation of $\mathrm{m}$ and $\mathrm{t}$ for samples cured under $120^{\circ} \mathrm{C}$ and $1.5 \mathrm{~h}$.

keep increasing sharply until breakdown, although the electric field is constant. Such a phenomenon can be called degradation of ZnO varistors with epoxy powder coating. The longrange data reveal that the sample failed after $300 \mathrm{~h}$ stress. It appears from this observation that the pressurised vapour method can be regarded as an accelerated process of the normal method.

The result of the $\mathrm{ZnO}$ varistors employing the water boiling method is quite different from the other two results. Within the first $2 \mathrm{~h}$ the leakage current is low. Instead of remaining at the same value of the leakage current it starts to increase after $2 \mathrm{~h}$. The overall trend of $\mathrm{m}$ is similar to that of the normal method. From this observation it can be concluded that there may exist three distinct plausible processes in the degradation of the $\mathrm{ZnO}$ varistors coated with the epoxy resin powder: $m$ changes slightly in the beginning of the process, then it keeps almost unchanged or slowly increases for a long time, and finally the leakage current reaches the specific value and the samples fail. N evertheless, the initial increase or decrease in the leakage current implies a sharp process that is not well understood. Indeed the pressurised vapour method caused a rapid failure though it had an intermediate level start within the first $2 \mathrm{~h}$. It is worth noting that the samples prepared employing curing temperatures and processing duration time for three extreme experimental methods may cause some form of degradation. Depending on the severity of the failure mechanism it is possible to ascertain suitable curing temperatures and processing duration times.

\subsection{The Influence of Curing Condition of Epoxy Resin Layer}

The role of the curing process of the epoxy resin coating in the degradation of the $\mathrm{ZnO}$ varistors is also investigated. Figures 2 and 3 depict the dependence of $\mathrm{m}$ on the leakage current time, t. Under the normal method condition (Fig. 2) and the pressurised vapour method 


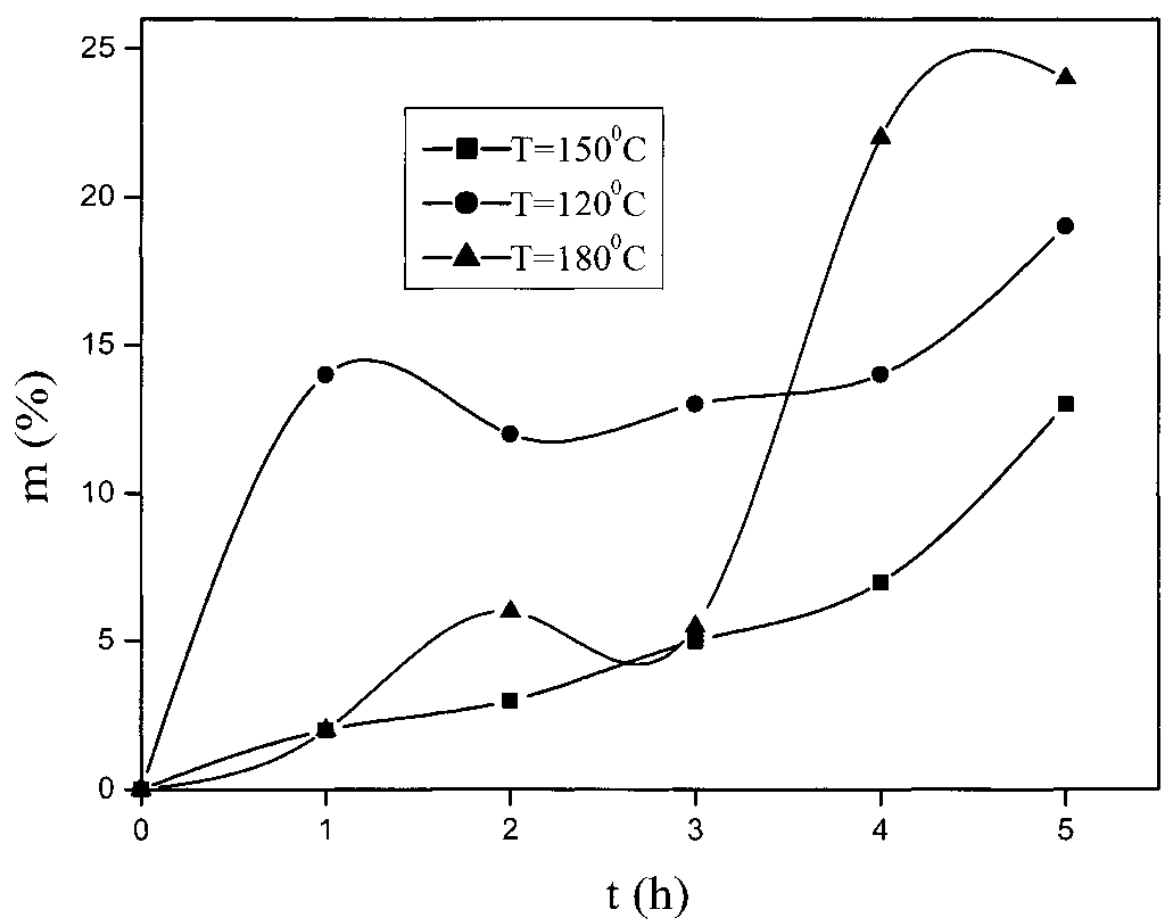

FIGURE 2 Dependence of $m$ on $t$ under the normal method condition.

condition (Fig. 3) the sample prepared at $150^{\circ} \mathrm{C}$ with any processing duration time yields a better performance. This is evidenced by the lowest value of $\mathrm{m}$ although the sample approaches eventual thermal runaway.

Figure 4 also shows the influence of the curing time on the water absorption ratio $n$ using the pressurised vapour method for the sample prepared with a fixed curing temperature of $150^{\circ} \mathrm{C}$. It yields an improved insulation coating of the $\mathrm{ZnO}$ varistor disc. There al so exists an optimal curing duration between $1.5 \mathrm{~h}$ and $2.0 \mathrm{~h}$ and subsequent increase of the curing duration may lead to further minor decrease or no change of $n$.

The curing temperatures $120^{\circ} \mathrm{C}$ and $180^{\circ} \mathrm{C}$ do not give better-coated samples as the coating is likely to be responsible for the resulting degradation of the $\mathrm{ZnO}$ varistor discs. This is affirmed from the usage of the identical sample throughout this study where the recipe, processing variables, dimension of the discs, etc. remained unchanged. It is clear that there exists a most suitable curing temperature, which is about $150^{\circ} \mathrm{C}$ inferred from Figures 2-4. The increase or decrease of curing temperature will both lead to an accelerated degradation. This is attributed to the possible poor insulation coating formation on to the $\mathrm{ZnO}$ varistor disc surfaces.

\subsection{The Degradation M echanism of ZnO Varistors Coated with Epoxy Resin L ayer}

When the epoxy coating of the failed sample is removed carefully by pilling off from the surfaces of the $\mathrm{ZnO}$ varistor disc, moisture content is observed. This moisture content on the disc surfaces is responsible for the increased leakage current, thereby causing degradation. The moisture or vapour outside the coating diffuses to the surface of the 


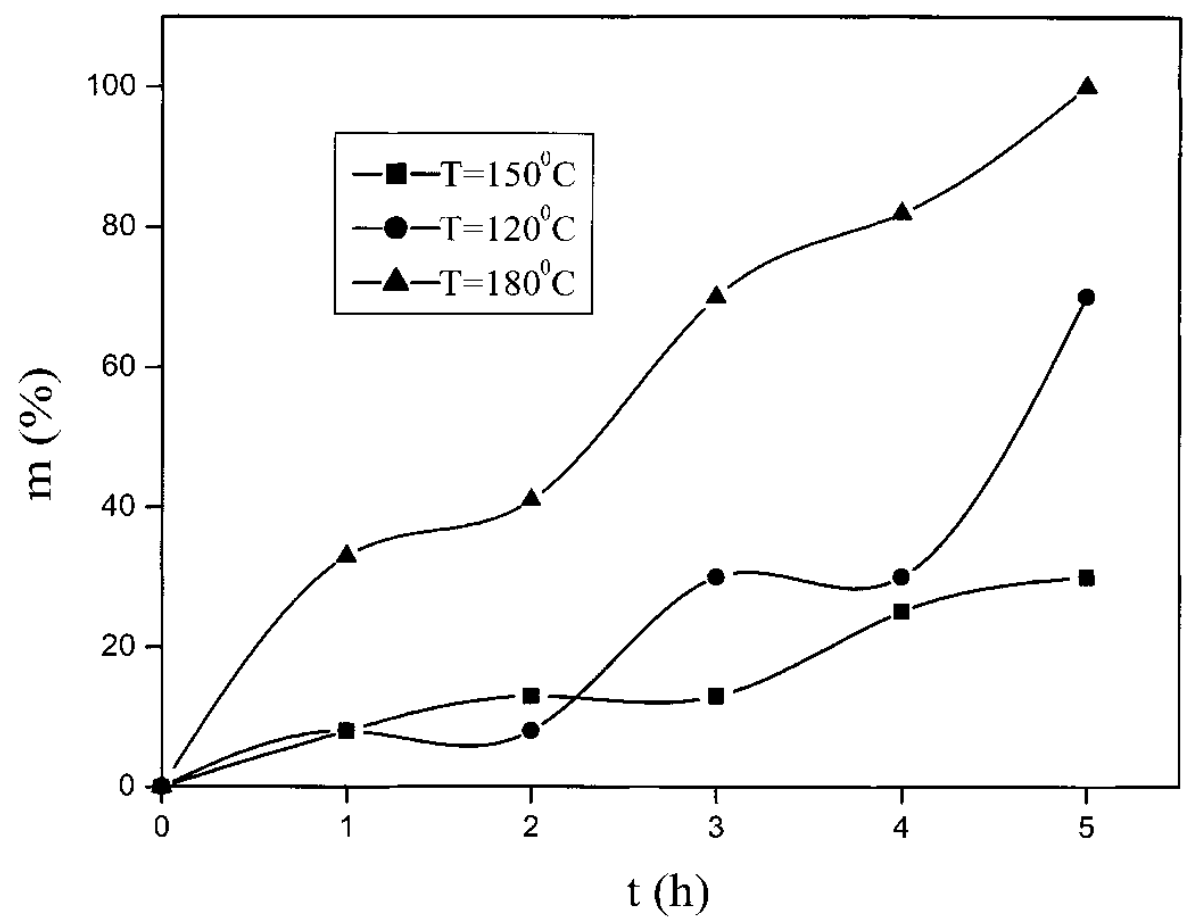

FIGURE 3 Dependence of $m$ on $t$ under the pressurised vapour method condition.

Zno ceramic disc through the epoxy resin coating. This diffusion process forms a water (moisture or vapour) film at the interface between the $\mathrm{ZnO}$ ceramic and the epoxy resin coating. The water ionises under the application of the electrical stress (electric field) and supplies carriers to enhance the leakage current. The equation of ionisation follows as:

$$
\mathrm{H}_{2} \mathrm{O} \rightarrow \mathrm{H}^{+}+(\mathrm{OH})^{-} \text {. }
$$

The mechanism of moisture penetration through the epoxy resin layer is more than likely to be governed by the pores or structural flaws, which were formed during the curing process, of the epoxy resin coating. This penetrating capability of the moisture content can be described in terms of the diffusion process of the water molecules on to the ZnO ceramic disc surfaces underneath the epoxy resin coating. From such a hypothesis it may be concluded that the level of porosity or structural flaws may remain at a minimum if the optimal processing condition of the epoxy resin is established via the combination of curing temperature and curing time. A ny deviation of achieving the optimum structural flaws of the epoxy resin coating material can give rise to the degradation process. Nevertheless, such a degradation will be attributed to the lack in adhesion of the epoxy resin which traps some amount of air or leaves some finite voids between the $\mathrm{ZnO}$ varistor disc surface and the epoxy resin coating. It is absolutely necessary to ascertain the structural flaws of the epoxy coating materials that are applied to the $\mathrm{ZnO}$ varistor discs for continued application purposes as the ambient condition may be severe depending on the places of application.

However, there may exist different operating ways of the three methods to cause additional fascinating results. In the normal method and the pressurised vapour method, water is present 


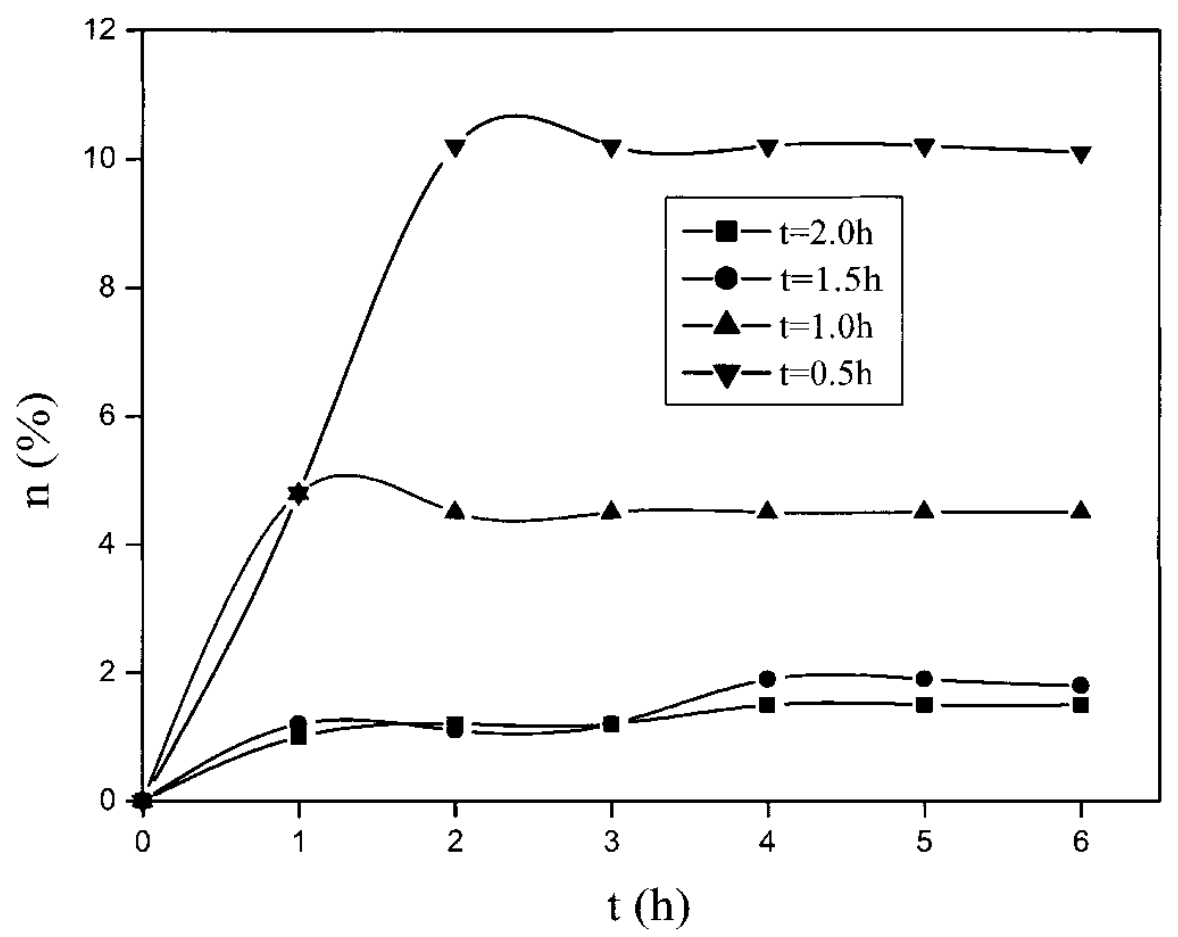

FIGURE 4 Influence of curing time on $\mathrm{n}$ under pressurised vapour method for samples cured at $150^{\circ} \mathrm{C}$.

in a vapour state, while in the water boiling method, water acts in a liquid state. The existing air molecules in the pores or in the structural flaws of the epoxy coating surfaces prevent the liquid water from transportation. Thus, the water boiling method leads to a slower degradation attributing to a smaller amount of diffusion of the moisture on the $\mathrm{ZnO}$ varistor surfaces. Figure 5 shows a result of leakage current measurement on vacuum-treated samples. In this schematic the bottom curve is obtained as a result of the water boiling method shown in Figure 1. The top curve is obtained from the water boiling method, except that the samples were treated with vacuum before putting in the boiling water. The general shape of the bottom curve is similar to the pressurised vapour method. This behaviour can explain why there will be differences among the three experimental methods. Invariably the surface porosity of the epoxy resin material for various curing conditions needs structural studies including microscopy to ascertain the present observations.

The degradation at el evated temperatures and ambient conditions can be regarded as a process of ageing for electrical insulating materials. Generally the life $(L)$ of various electrical insulating materials, in terms of time, can be expressed as a function of elevated temperatures ( $T$ ) and vapour pressure ( $p)[20]$ :

$$
L=K_{1}\left(\frac{1}{p^{\alpha} \top^{\beta}}\right)
$$

where $\mathrm{K}_{1}, \alpha, \beta$ are all constants and depend on the electrical insulating material itself.

In the case of varistor degradation discussed in this paper, the value of $\mathrm{m}$ can be considered dependent on three parameters: pressure $p$, temperature $T$ and time $t$. In order to compare the 


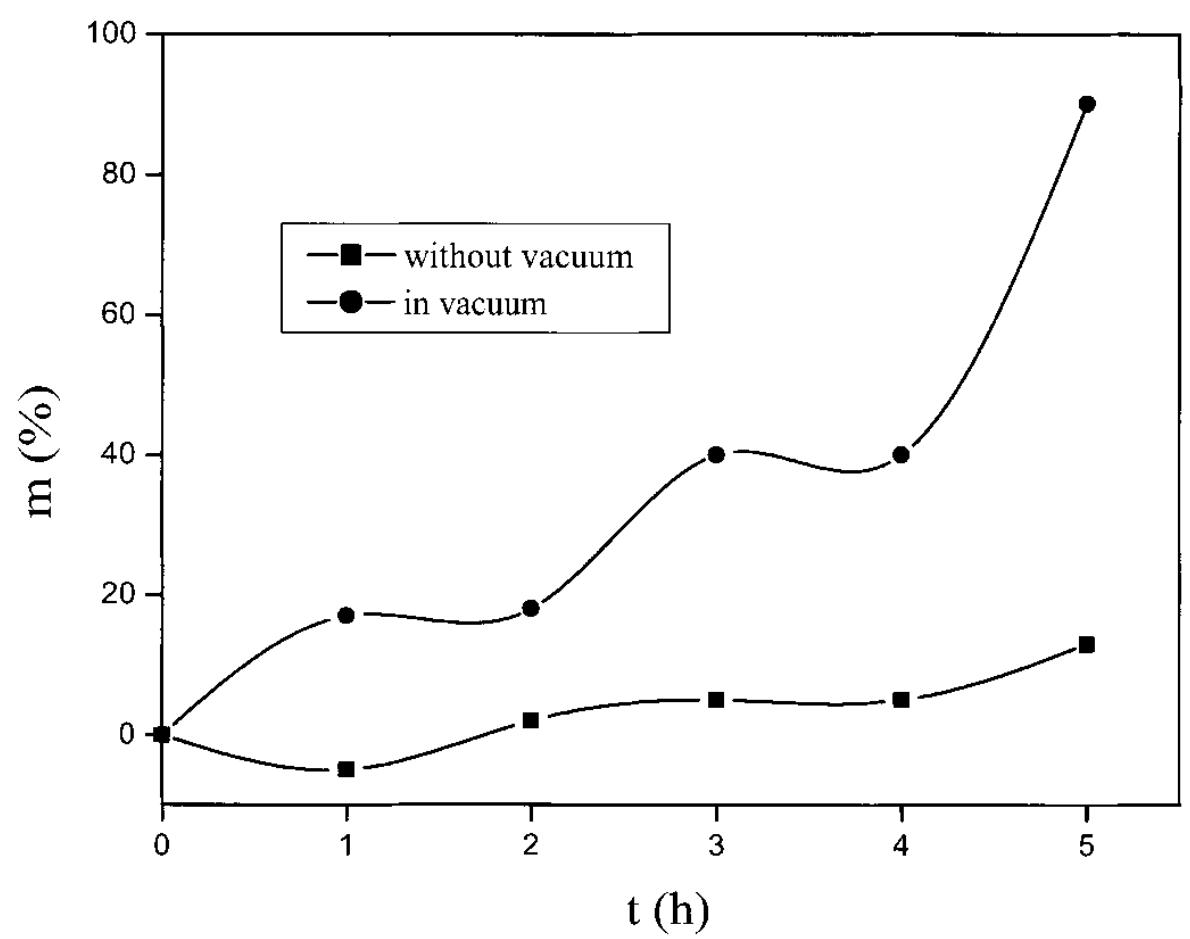

FIGURE 5 The effect of vacuum on $\mathrm{m}$-t relation.

roles of pressure and temperature, Eq. (5) is considered as a reference and the exponent of time $t$ is assumed to be 1 . Consequently the value of $\mathrm{m}$ can be expressed as follows:

$$
m=K_{2} p^{\alpha} \beta_{t}
$$

where $\mathrm{K}_{2}$ is also a constant that depends on the epoxy resin material. It is worth noting that the increase of $p$ and $T$ will lead to a decrease of life for general electrical insulating materials but an increase of $m$ for varistors. That is why Eqs. (4) and (5) show different formats.

It is assumed that the degradation mechanisms of the normal method and pressurised vapour method are identical. This is due to the nature of the degraded curves that are obtained. Considering the curves with a curing temperature of $150{ }^{\circ} \mathrm{C}$ in Figures 2 and 3 , it can be calculated that $\alpha=1.05$ and $\beta=5.28$, indicating that the role of temperature in degradation is much more important than that of the vapour pressure.

\section{CONCLUSIONS}

ZnO varistors coated with epoxy resin degrade at elevated temperatures and ambient humidity conditions. The pressurised vapour method leads to a rapid degradation compared to the normal method and the water boiling method. There exists a suitable curing temperature and curing duration of the epoxy resin powder, which can improve the degradation performance.

Water acts as a vapour in the normal method and pressurised vapour method while it is a liquid in the water boiling method. Such a difference provides variation in the experimental results due to the trapped air in the pores or structural flaws (cracks) of the epoxy resin layer. 
An equation, $L=K_{1}\left(1 / p^{\alpha} T^{\beta}\right)$, can be used to describe the degradation of the $Z n 0$ varistors coated with epoxy resin at elevated temperatures and various ambient humidity conditions. It can also be calculated that $\alpha=1.05$ and $\beta=5.28$, indicating that the role of temperature is much more dominant and important than that of the vapour pressure.

\section{References}

[1] Eda, K., Iga, A . and M atsuoka, M . (1980). Degradation mechanism of non-ohmic zinc oxide ceramics. J ournal of Applied Physics, 51(5), 2678-2684.

[2] Tomimuro, H. and Terasaki, Y. (1979). Degradation mechanism of ZnO varistors. Japanese J ournal of Applied Physics, 18\#8, 1653-1654.

[3] Philipp, H. R. and Levinson, L. M. (1983). Degradation phenomena in zinc oxide varistors: A review. In: Yan, M. F. and Heuer, A. H. (Eds.), Advances in Ceramics - Additives and Interfaces. Vol. 7, pp. 1-21.

[4] Bather, K. H., B ruckner, W., M oldenhauer, W. and B ruckner, H. P. (1983). M icroscopic degradation model for ZnO varistors. Physica Status Solidi (a), 75, 465-472.

[5] B ruckner, W., M oldenhauer, W. and Bather, K. H. (1982). Time dependence of degradation in ZnO varistors. Physica Status Solidi (a), 70, 167-175.

[6] Shirley, C. G. and Paulson, W. M. (1979). The pulse-degradation of ZnO varistors. J ournal of Applied Physics, 50(9), 5782-5789.

[7] Hayashi, M., Haba, M., Hirano, S., Okamato, M. and Watanabe, M. (1982). Degradation mechanism of zinc oxide varistors under dc bias. J ournal of Applied Physics, 53\#8, 5754-5762.

[8] Tanaka, J., Hishita, S. I. and Okushi, H. (1990). Deep levels near the grain boundary in a zinc oxide varistor: Energy change due to electrical degradation. J ournal of the American Ceramic Society, 73(5), 1425-1428

[9] Sato, K. and Takada, Y. (1982). A mechanism of degradation in leakage currents through ZnO varistors. J ournal of Applied Physics, 53(12), 8819-8826.

[10] Hampton, F. L. (1979). A study of the variables influencing the durability of ZnO based varistors. PhD dissertation, M arquette University, M ilwaukee, WI, USA.

[11] Kim, E. D., Oh, M. H. and Kim, C. H. (1986). Effects of annealing on the grain boundary potential barrier of ZnO varistor. J ournal of Materials Science, 21, 3491-3496.

[12] A sokan, T. and Freer, R. (1993). Grain and grain boundary conduction in zinc oxide varistors before and after DC degradation. J ournal of the European Ceramic Society, 11, 545-550.

[13] Gupta, T. K. and Carlson, W. G. (1985). A grain boundary defect model for instability/stability of a ZnO varistor. J ournal of Material Science, 20, 3487-3500.

[14] Gupta, T. K . and M iller, A. C. (1988). Improved stability of ZnO varistors via donor and acceptor doping at grain boundaries. Journal of Material Research, 3, 745-754.

[15] Sokoly, T. O., Seitz, M. A ., Guertin, J. P., Schumacher, P. P. and Potter, M . E. (1980). Development of a New Type of Nonlinear Resistance Valve Block for Surge Arresters. EPRI Final Report, EL-1647, Project 425-1, December 1980.

[16] Stucki, F. and Greuter, F. (1990). Key role of oxygen at zinc oxide varistor grain boundaries. Applied Physics Letters, 57, 446-448.

[17] Seitz, M. A., Hirthe, R. W. and Potter, M. E. (1982). Thermal runaway in metal oxide varistors. In: L eamy, H. J., Pike, G. E. and Seager, C. H. (Eds.), M aterials Research Society Symposia Proceedings, Vol. 5, pp. 405-410.

[18] Popescu, C. (1970). Selfheating and thermal runaway phenomena in semiconductor devices. Solid State Electronics, 13, 441-450.

[19] Popescu, C. (1970). The thermal runaway mechanism of second breakdown phenomenon. Solid State Electronics, 13, 887-901.

[20] Yaonan Liu and Changrong Qiu (1981). Testing M ethods of Electrical Insulation. M echanical Industry Press, P.R. China. 

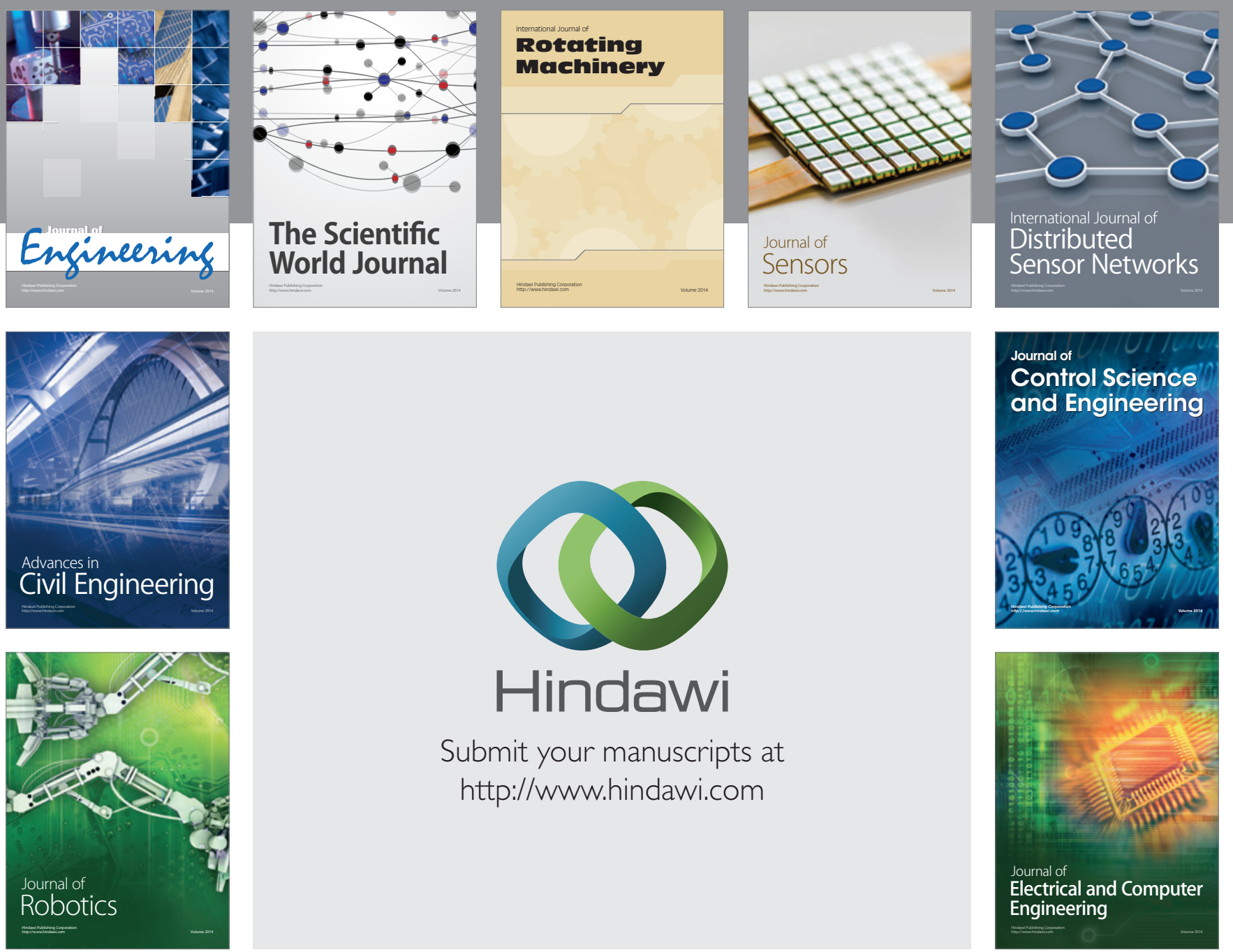

Submit your manuscripts at

http://www.hindawi.com
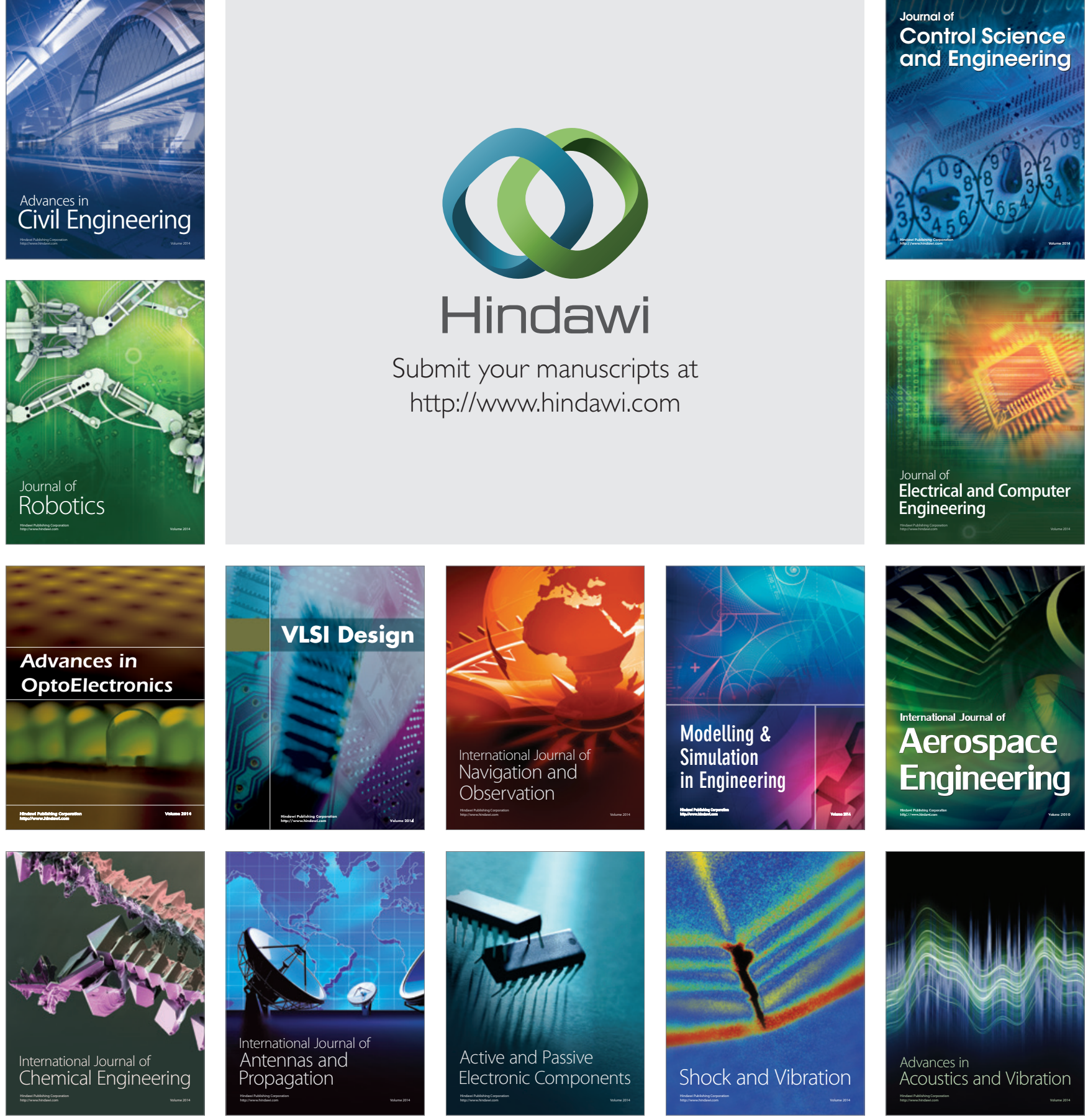